\title{
Evaluating User Satisfaction Based on BP Neural Network in Mobile Government
}

\author{
Wenwen $\mathrm{Li}$ \\ Beihang University \\ School of Economics and Management \\ Beijing, China \\ liwwen007@hotmail.com
}

\author{
Yunxia Pan \\ Beihang University \\ School of Economics and Management \\ Beijing, China \\ simuzhiyan@gmail.com
}

\begin{abstract}
With the explosion in the use of mobile technologies, more people can get m-government services. It is related to the interests of many people, so it is necessary to evaluate user satisfaction of the services. Some proposed models fail to evaluate the m-government from the public's perspective. The purpose of this study is to create an evaluation model to evaluate user satisfaction of m-government. Based on the theory of SERQUAL and Kano model, an evaluation model was established and the indicators are grouped into five constructs: activity; convenience; friendliness; reliability and responsiveness. Then we conducted a questionnaire survey to test the model. To make the evaluation more objective, we use a quantitative evaluation method, the BP neural network, to develop, test and validate on $14 \mathrm{M}$-government platforms. And the results confirm that this model can be put into practice. This study has given us a direction to improve the user satisfaction of $\mathbf{m}$-government.
\end{abstract}

Keywords- user satissfaction; m-government; BP neural network

\section{INTRODUCTION}

Recent years, with the rapid growth of use of wireless and mobile networks and devices [1], people spend more time on mobile devices. Use of mobile technologies has enabled governments to transit from e-government to mobile government [2].

M-government is quickly emerging as the new frontier of service delivery [3]. Though, m-government is still in its early stages, it has begun to transform the delivery of public services [4]. Thus, user satisfaction is important in the development of m-government. Therefore, an evaluation model which includes 'knowhow' factors affecting user satisfaction is necessary.

To spread m-government services, the choice of both technology and services should correspond to the real needs of the people [5]. Therefore m-government services should be evaluated from the users' perspective.

In the following sections, we first build an evaluation model, and select WeChat as an example to verify the validity of evaluation model. Then we will present our conclusion and suggestions for m-government's further development.

\section{EVALUATION SYSTEM CONSTRUCTION}

\section{A. Initial evaluation system}

We evaluate m-government from two different perspectives, government and public, by an evaluation model based on SERVQUAL model.

Customer satisfaction and service quality research is dominated by SERVQUAL, which suggests that service quality is fundamentally a gap between customer expectations [6].

TABLE I. INITIAL EVALUATION MODEL

\begin{tabular}{|c|c|c|}
\hline Perspective & Construct & Reflective Measures \\
\hline \multirow{7}{*}{$\begin{array}{c}\text { User } \\
\text { satisfaction }\end{array}$} & activity & $\begin{array}{l}\text { Pushing various information } \\
\text { Pushing information timely }\end{array}$ \\
\hline & convenience & $\begin{array}{l}\text { Being easily operated on } \\
\text { martnhnne } \\
\text { Needing few steps to complete } \\
\text { Navigation is easily used to find }\end{array}$ \\
\hline & friendliness & 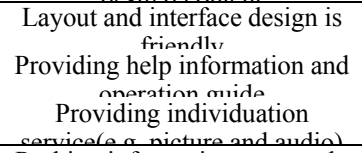 \\
\hline & \multirow{2}{*}{ reliability } & Pushing information accurately \\
\hline & & Content of information is \\
\hline & \multirow{2}{*}{ responsiveness } & Providing manual service timely \\
\hline & & $\begin{array}{c}\text { Providing additional } \\
\text { sommunication } \mathrm{channels}\end{array}$ \\
\hline \multirow{2}{*}{$\begin{array}{l}\text { Team } \\
\text { building }\end{array}$} & integrity & $\begin{array}{c}\text { Containing developers and } \\
\text { maintenance norcnnnel } \\
\text { Having customer service to } \\
\text { nrovide human cervice }\end{array}$ \\
\hline & technical & $\begin{array}{c}\text { Staffs have certain skills } \\
\text { Staffs have plenty of experiences }\end{array}$ \\
\hline \multirow{3}{*}{$\begin{array}{l}\text { Platform } \\
\text { marketing }\end{array}$} & promotion & $\begin{array}{c}\text { Having a popularity } \\
\text { Attracting public attention }\end{array}$ \\
\hline & $\begin{array}{l}\text { Followers } \\
\text { increment }\end{array}$ & $\begin{array}{l}\text { The average increase in the } \\
\text { number of followers }\end{array}$ \\
\hline & image & $\begin{array}{l}\text { Receiving enough public } \\
\text { rannnition } \\
\text { Public prefer to trust it }\end{array}$ \\
\hline \multirow[t]{2}{*}{ content } & authority & $\begin{array}{l}\text { Publish content on behalf of the } \\
\text { mavarnmant viaurs } \\
\text { Source of information is reliable }\end{array}$ \\
\hline & targeted & User customization \\
\hline
\end{tabular}

Activity is defined as how often WeChat pushes messages. 
Convenience is defined as how convenient the WeChat is for public. WeChat is used on the smartphone, it should be convenient for public to use on small screen.

Friendliness is defined as how friendly public feel. We chose the factor that is generally accepted as a standard of friendliness, such as the polite language.

Reliability is defined based on the accuracy and completeness of the massages. Unreal and one-sided information will mislead the public.

Responsiveness refers to timely response to users. Timely feedback can save time.

Although SERVQUAL model can be used to evaluate the quality of service, it has its limitations because of that importance of each indicator is different. To compensate for this, we adopted the Kano model.

\section{B. Kano Model}

This theory focused the attention on the attributes considered more important by customers in order to improve them [7]. Sulisworo has integrated Kano's model to improve healthcare service quality [8].

Understanding customer's expectations and how they feel about the products they use has become more important [9]. So in the study, we screened for the indicators that have impact on the user satisfaction and classified them into three groups namely basic, performance and delight.

\section{Questionnaire survey}

This study refers to Kano model evaluation form and establishes the applicable evaluation form (Table 2) to analyze.

"M" means "Must-have", and represents the basic needs. "R" means "Reverse". Reverse results expresses strong dissatisfaction. "L" means "Linear". It stands for the expected demand that users expect to be met. "Q" means "Questionable". More than two Q appear, it will be regarded as an invalid questionnaire. "E" means "Exciter". Once satisfied, it will greatly enhance the user experience. "I" means "Indifferent", and users do not care about it.

TABLE II. KANO MODEL EVALUATION FORM

\begin{tabular}{|c|c|c|c|c|c|c|}
\hline \multirow{2}{*}{\multicolumn{2}{|c|}{ User satisfaction }} & \multicolumn{5}{|c|}{ Dysfunctional questions (bad experience) } \\
\hline & & Like & Expect & Neutral & Live with & Dislike \\
\hline \multirow{5}{*}{$\begin{array}{l}\text { Functional } \\
\text { questions(good } \\
\text { experience) }\end{array}$} & Like & $\mathrm{Q}$ & $\mathrm{E}$ & $\mathrm{E}$ & $\mathrm{E}$ & $\mathrm{L}$ \\
\hline & Expect & $\mathrm{R}$ & I & I & I & $\mathrm{M}$ \\
\hline & Neutral & $\mathrm{R}$ & I & $\mathrm{I}$ & I & $\mathrm{M}$ \\
\hline & Live with & $\mathrm{R}$ & $\mathrm{I}$ & $\mathrm{I}$ & $\mathrm{I}$ & $\mathrm{M}$ \\
\hline & Dislike & $\mathrm{R}$ & $\mathrm{R}$ & $\mathrm{R}$ & $\mathrm{R}$ & Q \\
\hline
\end{tabular}

\section{Data Analysis}

First we count the number of attributes for corresponding indicator, and select the biggest number of attributes as the indicator's attributes. And calculate the Better-worse coefficient. Better coefficient value means that if they meet certain targets, user satisfaction will be enhanced. And worse coefficient is just the opposite. The answer is calculated as follows (Table 3):

$$
\begin{gathered}
\text { Better }=(E+L) /(E+L+M+I) \\
\text { Worse }=\frac{L+M}{E+L+M+I} \times(-1)
\end{gathered}
$$

Keep down indicators whose attributes are E, M and L. "Push message accurately" is a basic need. "Less query step", "Easy to find what you need with navigation", and "A friendly layout and page design" are performance needs. "Push message in time" and "Operating easily with smartphone" belong to delighters.
TABLE III. KANO MODEL

\begin{tabular}{|c|c|c|c|}
\hline The third level indicators & $\begin{array}{c}\text { Final } \\
\text { attribute }\end{array}$ & better & worse \\
\hline Pushing various messages & $\mathrm{I}$ & 0.42 & -0.38 \\
\hline Pushing messages timely & $\mathrm{E}$ & 0.62 & -0.44 \\
\hline $\begin{array}{c}\text { Being easily operated on } \\
\text { smartphone }\end{array}$ & $\mathrm{E}$ & 0.6 & -0.28 \\
\hline $\begin{array}{c}\text { Needing few steps to complete } \\
\text { query }\end{array}$ & $\mathrm{L}$ & 0.42 & -0.72 \\
\hline $\begin{array}{c}\text { Navigation is easily used to } \\
\text { find desired content }\end{array}$ & $\mathrm{L}$ & 0.48 & -0.54 \\
\hline $\begin{array}{c}\text { Layout and interface design is } \\
\text { friendly }\end{array}$ & $\mathrm{L}$ & 0.58 & -0.66 \\
\hline $\begin{array}{c}\text { Providing help information and } \\
\text { operation guide }\end{array}$ & $\mathrm{I}$ & 0.3 & -0.42 \\
\hline $\begin{array}{c}\text { Providing individuation } \\
\text { service(e.g. picture and audio) }\end{array}$ & $\mathrm{I}$ & 0.43 & -0.16 \\
\hline $\begin{array}{c}\text { Pushing messages accurately } \\
\text { Content of message is complete }\end{array}$ & $\mathrm{M}$ & 0.44 & -0.78 \\
\hline $\begin{array}{c}\text { Providing manual service } \\
\text { timely }\end{array}$ & $\mathrm{I}$ & 0.42 & -0.35 \\
\hline $\begin{array}{c}\text { Providing additional } \\
\text { communication channels }\end{array}$ & $\mathrm{I}$ & 0.41 & -0.18 \\
\hline
\end{tabular}

\section{E. Evaluation system}

The third level indicators give a detailed description of the second level indicators. Based on the above analysis, the evaluation model was constructed as follows. 
TABLE IV. KANO MODEL EVALUATION FORM

\begin{tabular}{|c|c|c|c|}
\hline $\begin{array}{l}\text { The first level } \\
\text { indicators }\end{array}$ & $\begin{array}{c}\text { The second } \\
\text { level indicators }\end{array}$ & The third level indicators & Grading criterion \\
\hline \multirow{6}{*}{$\begin{array}{l}\text { User } \\
\text { satisfaction } \\
\text { evaluation } \\
\text { indicators }\end{array}$} & Activity & Pushing messages timely & $\begin{array}{l}\text { Count the number of messages during } \\
2014.1 .1-2014.3 .21\end{array}$ \\
\hline & Friendliness & Layout and interface design is friendly & $\begin{array}{l}\text { The attitude of the service terms are friendly } \\
\text { or not; options box is simple or not; quality of }\end{array}$ \\
\hline & Reliability & Pushing message accurately & $\begin{array}{l}\text { During } 2014.1 .1-2014.3 .21 \text {, calculate the } \\
\text { percentage of messages that meet the theme. } 0\end{array}$ \\
\hline & \multirow{3}{*}{ Convenience } & Being easily operated on smartphone & \multirow{3}{*}{$\begin{array}{l}\text { An average number of steps required for } \\
\text { querying information or a service. }\end{array}$} \\
\hline & & Needing few steps to complete query & \\
\hline & & $\begin{array}{l}\text { Navigation is easily used to find desired } \\
\text { content }\end{array}$ & \\
\hline
\end{tabular}

To make the model can be used for quantitative assessment and to ensure the objectivity of the evaluation, we make a list of scoring criteria. Because the majority of governmental WeChat has navigation so we do not consider the impact of the navigation. Thus, the evaluation of convenience mainly refers to the number of querying steps.

\section{METHOD}

An artificial neural network is an information processing system simulating human brain structure and function [10]. BP neural network, based on error back propagation algorithm of artificial neural network, is proposed by Rumelhart et al [11]. Because of its good self-adaptive, self-learning, parallel processing and nonlinear computing capacity, BP neural network has been widely used. Since evaluating user satisfaction in m-government is an uncertain and nonlinear problem, BP neural network can be used.

The topology structure of basic BP neural network mainly composed by the input layer, hidden layer and output layer. Its transfer function of neurons is an S-type function, and its output is a continuous variable between 0 and 1 . BP network is a multilayer feed forward feedback neural network, which avoids the limitations of regression method and accurately establishes the mapping relations between the input and output variables [10]. A description of the neural network algorithm steps is as follows:

a) Initialize the network: set the error function $e$, the precision value $\varepsilon$, the maximum number of learning $M$. And assign weight values to random numbers between -1 and 1 .

b) Select the $k$ th input sample and output sample:

$$
\begin{gathered}
x(k)=\left(x_{1}(k), x_{2}(k), \cdots, x_{n}(k)\right) \\
d_{0}(k)=\left(d_{1}(k), d_{2}(k), \cdots, d_{q}(k)\right)
\end{gathered}
$$

c) Calculate the input and output from neurons in the hidden layer:

$$
\begin{gathered}
h i_{h}(k)=\sum_{i=1}^{n} w_{i h} x_{i}(k)-b_{h}, \quad h=1,2, \cdots, p \\
h o_{h}(k)=f\left(h i_{h}(k)\right), h=1,2, \cdots, p \\
y i_{o}(k)=\sum_{h=1}^{p} w_{h o} h o_{h}(k)-b_{o}, o=1,2, \cdots, q \\
y o_{o}(k)=f\left(y i_{o}(k)\right), o=1,2, \cdots, q
\end{gathered}
$$

Where $f()$ is the sigmoid transfer function given by $f(x)=1 /\left(1+e^{-x}\right) . w_{i h}$ is the weight from the input layer to hidden layer. $w_{h o}$ is the weight form the hidden layer to output layer. $b_{h}$ is the threshold of the hidden layer. $b_{o}$ is the threshold of the output layer.

d) Use desired output, actual output and weights to calculate the partial derivatives $\delta_{0}(k), \delta_{h}(k)$

e) Adjust weights:

$$
\begin{gathered}
w_{h o}^{N+1}=w_{h o}^{N}+\eta \delta_{O}(k) h o_{h}(k) \\
w_{i h}^{N+1}=w_{i h}^{N}+\eta \delta_{h}(k) x_{i}(k)
\end{gathered}
$$

f) Algorithm will finish when the network error reaches the pre-set precision or the number of learning is bigger than a pre-set value. Otherwise, turn to the 3 th step.

BP neural network method of m-government user satisfaction evaluation model is shown in figure 1. First we select WeChat to collect data. Input data to the BP neural network after its normalization. The learning process can be roughly divided into two phrases: the forward propagation of information and the backward propagation of error [12]. The BP neural network passed the inspection can be used for the evaluation. 


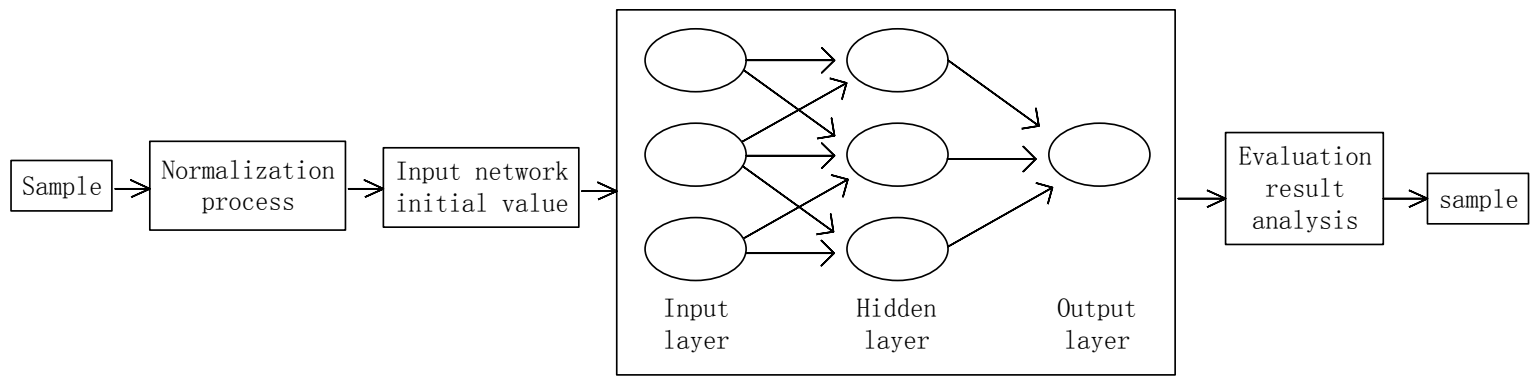

Figure 1. Structure model of BP neural network

\section{ANALYSIS AND RESULTS}

The applications of Neural Network Toolbox will improve work efficiency and accuracy and precision of calculation. This article will use the functions for training and simulation learning of the BP neural network.

\section{A. BP neural Network model design}

There are four evaluation indicators, therefore the number of neurons in the input layer $P_{n}$ is 4 . As the only output of the network, evaluation results are divided into "qualified" (0.9) and "fail" (0.1). The number of neurons in the output layer is 1 .

Hornik has proved that if the input and output layers use a linear transfer function and hidden layer uses Sigmoid transfer function, the MLP network with a hidden layer can approach any rational function with arbitrary precision. Referring to the conclusion, this paper designed BP neural network with three layers (that means only 1 hidden layer). Currently, there is no accurate algorithm for calculating the number of neurons in hidden layer. Based on experience, the number of neurons in the hidden layer is generally $2 n+1$ at least (n stands for the number of input neurons). And must be less than $\mathrm{N}-1$ ( $\mathrm{N}$ is the number of training samples). Considering learning time, frequency and overall total error, this paper selects nine hidden layer neurons.

\section{B. Sample selection and data sources}

This paper selected seven outstanding governmental WeChat and seven governmental WeChat of poor quality in Guangdong province as sample. The ten governmental WeChat are recognized by the citizens. All sources of data are based on the actual analysis.

\section{Model trainong}

Since this paper uses Sigmoid transfer function, the general requirement of the input data values is that it should be between 0 and 1 in order to improve the speed and agility of training, and avoid the saturation region of Sigmoid function. Therefore, we firstly normalized the input data, and the normalized function is shown as follow.

[normInput, ps] = mapminmax $(\mathrm{p})$;

Select the top 10 groups in table 2 as training samples, and the remaining 4 groups as test samples. Large learning rate will make every correction of network weights is too large, or even lead to convergence; small learning rate will lead to long learning time. In this paper, we makes the learning rate $\varepsilon=0.01$, training times $\mathrm{N}=10000$, and the training objectives is $1 \mathrm{e}-6$.

As the initialized weights and thresholds are randomly generated, so the training results are not the same for each time. This paper conducted 10 times of training, and we selected the best results and save the network.

The training results are shown in table 5. Training error is reduced to $2 \%$ or less, and it is within the acceptable range, so the learning requirements have been met.

TABLE V. KANO MODEL EVALUATION FORM

\begin{tabular}{|c|c|c|c|}
\hline No. & Training result & Desired output & Relative error (\%) \\
\hline $\mathbf{1}$ & 0.89966 & 0.9 & 0.03778 \\
$\mathbf{2}$ & 0.90000 & 0.9 & 0.00000 \\
$\mathbf{4}$ & 0.90000 & 0.9 & 0.00000 \\
$\mathbf{5}$ & 0.90000 & 0.9 & 0.00000 \\
$\mathbf{6}$ & 0.89988 & 0.9 & 0.01333 \\
$\mathbf{7}$ & 0.10003 & 0.1 & -0.03000 \\
$\mathbf{8}$ & 0.10177 & 0.1 & -1.77000 \\
$\mathbf{9}$ & 0.10001 & 0.1 & -0.01000 \\
$\mathbf{1 0}$ & 0.10003 & 0.1 & -0.03000 \\
\hline
\end{tabular}


After applying the test sample to the trained model, the results obtained are shown in table 6. Analysis shows that the relative error is less than $0.003 \%$, therefore network learning presents good effect. The model constructed based

TABLE VI. KANO MODEL EVALUATION FORM

\begin{tabular}{|c|c|c|c|}
\hline No. & Training result & Desire result & Relative error \\
\hline $\mathbf{1 1}$ & 0.89999 & 0.9 & 0.00111 \\
$\mathbf{1 2}$ & 0.89998 & 0.9 & 0.00222 \\
$\mathbf{1 3}$ & 0.10001 & 0.1 & -0.01000 \\
$\mathbf{1 4}$ & 0.10000 & 0.1 & 0.00000 \\
\hline
\end{tabular}

\section{DISCUSSION}

\section{A. Findings}

This study makes the following contributions:

1. It proposes an evaluation model which includes four indicators: user satisfactions, team working, platform marketing and content. The center of our research is the user satisfaction. Further it can identify weak areas, improve them with target and enhance the user satisfaction.

2. This study uses quantitative analysis to evaluate m-government platform synthetically. This paper first proposes the use of BP neural network for quantitative analysis to evaluate platform objectively.

\section{B. Advice to government}

As a medium for communication, it should be rational towards public. Through analysis of the data and research, government can create a platform that is closer to the public demand.

To achieve this goal, government needs to pay some efforts. Firstly, operational management should be strengthened. Secondly, the ability of service should be enhanced. Due to the dynamic internal and external environment, a good m-government requires continuous evaluation. Therefore, we will be targeted for improvement. Thirdly, public demand is changing over time, and only keeping abreast of new demand can governmental WeChat keep pace with the times.

\section{Limitation and future research}

Our study has some limitations. First, the BP neural network was tested with a few samples. However, using more samples from different province also has limitations. User satisfaction may be related to other unobserved factors. Second, some indicators are unable to collect quantitative data. This forced us to measure these indicators qualitatively. Thus the results will be affected by the subjective feelings.

In the future research, we should test the reliability of the model in a wider range. Meanwhile, there are still some unresolved problems, such as the indicators susceptible to subjective feelings. This may need to take some ways to reduce the impact of these factors on BP neural network can be used to evaluate the user satisfaction of governmental WeChat.

\section{CONSLUSION}

The objective of this article is to evaluate user satisfaction of mobile government. Drawing upon previous studies and questionnaire survey about user satisfaction of WeChat, we constructed an evaluation model. The model demonstrates that user satisfaction is strongly influenced by activity, friendliness, reliability and convenience. Then we use the BP neural network. Applying BP neural network to user satisfaction evaluation is a new attempt in this study. The final results are consistent with the results that the Guangdong province announced. So it indicates that BP neural network is feasible for the evaluation of user satisfaction. These results contribute to giving government a method to evaluate m-government and letting government to improve user satisfaction of m-government in certain aspects.

\section{REFERENCES}

[1] Changlin Wang, "Antecedents and consequences of perceived value in mobile government continuance use", Computers in Human Behavior 34 (2014) 140-147.

[2] Silvana Trimi, Hong Sheng, "Emerging trends in m-government", Communications of the ACM, 2008.5.

[3] Desta Mengistu, Hangjung Zo, Jae Jeung Rho, "M-government: opportunities and challenges to deliver mobile government services in developing countries", 2009 Fourth International Conference on Computer Sciences and Convergence Information Technology.

[4] Ela Goyal, Seema Purohit, "Emergence of m-government-The way forward", SIES Journal of Management, 2012.3.

[5] Diana Ishmatova, Toshio Obi, "m-Government Services: User Needs and Value". I-Ways Journal of E-Government Policy Regulation 32 (2009) 39-46.

[6] Cronin, J. and Taylor, A.(1992), "Measuring service quality: a reexamination and extension", Journal of marketing, Vol.56, pp. 55-68.

[7] A. Parasuraman, Valarie A. Zeithaml, Leonard L. Berry, "SERVQUAL: A Multiple-Item Scale for Measuring Consumer Perceptions of Service Quality”, Journal of Retailing, Spring 1988.

[8] Xenia Papadomichelaki, Gregoris Mentzas, "e-Govqual: A multiple-item scale for assessing e-government service quality", Government Information Quarterly 29 (2012) 98-109.

[9] Sulisworo, D,(2000), "Integrating Kano's model and SERQUAL to improve healthcare quality".

[10] Kuo-Chien Chang, Mu-Chen Chen, Chia-Lin Hsu, "Identifying Critical Brand Contact Elements of a Tourist Destination: Applications of Kano's Model and the Importance-satisfaction Model", International Journal of Tourism Research, 205-221 (2012).

[11] Ping Zhang, Gisela von Dran, "Expectations and Rankings of Websites Quality Features: Results of Two Studies on User Perceptions", Proceedings of the 34th Hawaii International Conference on System Sciences-2001.

[12] Zhang Zhiyu, Liu Xinghua, Cui Yuechuang, Li Congdong, "Customer Relationship Evaluation System Based on BP Neural Network in electronic commerce", 2010 International Conference on E-Business and E-Government. 